\title{
Martensitic transformation in AISI D2 tool steel during continuous cooling to $173 \mathrm{~K}$
}

\author{
Hadi Ghasemi Nanesa ${ }^{\mathrm{a} 1}$, Mohammad Jahazi ${ }^{\mathrm{a} 2}$, Reza Naraghi ${ }^{\mathrm{b} 3}$ \\ ${ }^{a}$ Department of Mechanical Engineering, École de Technologie Supérieure, 1100 rue Notre-Dame Ouest, Montréal (QC) H3C 1K3 Canada. \\ ${ }^{\mathrm{b}}$ Department of Materials Science and Engineering, KTH Royal Institute of Technology, Brinellvägen 23, SE-10044 Stockholm, Sweden
}

\begin{abstract}
:
Martensitic transformation of AISI D2 tool steel continuously cooled from $1303 \mathrm{~K}$ to the cryogenic temperature of $173 \mathrm{~K}$ is investigated by dilatometry using $10 \mathrm{Ks}^{-1}$ or $50 \mathrm{Ks}^{-1}$ cooling rates. A 'typical' expansion takes place from the $M_{s}$ temperature and reaches a maximum at 325 K. However, an atypical behavior is observed below this temperature implying the activation of further martensitic transformation. A modification to existing equations is proposed, which allows for more accurate description of the kinetics of martensitic transformation. Scanning electron microscopic studies indicated the presence of plate and lath martensite for both cooling rates. Carbide precipitation takes place at the rate of $10 \mathrm{Ks}^{-1}$ before the start of martensitic transformation while it was not observed when the $50 \mathrm{Ks}^{-1}$ rate was used. Transmission electron microscopic studies revealed that the microstructure also contains a significant amount of nano twined martensite.
\end{abstract}

Keywords: Steel; In-situ dilatometer; Martensitic transformation; Kinetic; microstructure.

\section{Introduction}

AISI D2 tool steel is widely used in mold making industry as well as high speed cutting tools, where a combination of ultrahigh strength with high wear resistance and good toughness is required [1]. The conventional heat treatment of this steel consists of three main steps: 1) Solutionizing in the austenitic region (from $1273 \mathrm{~K}$ to $1313 \mathrm{~K}$ ) [2]; 2) Air or gas cooling to room

\footnotetext{
${ }^{1}$ Corresponding author. Tel.: + 514396 8974; fax: 514396 8530. E-mail address: hadi.ghasemi-nanesa.1@ens.etsmtl.ca.

2 Email: Mohammad.Jahazi@etsmtl.ca

3 Email: naraghi@kth.se
} 
temperature (close to $1 \mathrm{Ks}^{-1}$ [2]); 3) Single or double tempering (from $423 \mathrm{~K}$ to $823 \mathrm{~K}$ ) [3, 4]. The starting microstructure (i.e. the as-received condition) before hardening treatment is the annealed condition. In the annealed condition, the matrix is composed of ferrite and several types of carbides [2]. The larger or primary ones, $\mathrm{M}_{7} \mathrm{C}_{3}$, formed at the austenite grain boundaries and then dispersed as a result of hot working [2]. The other carbides, $\mathrm{M}_{2} \mathrm{C}$ and $\mathrm{M}_{23} \mathrm{C}_{6}$, are the result of secondary precipitation during normalizing heat treatment [5-7]. It must be mentioned that some authors have proposed a sub-classification of secondary carbides as "large" and "small" secondary carbides in D2 steel [5]. The formation of $\mathrm{MC}$ and $\mathrm{M}_{2} \mathrm{C}$ (similar chemical composition as $\mathrm{M}_{7} \mathrm{C}_{3}$ ), and $\mathrm{M}_{23} \mathrm{C}_{6}$ carbides are possible based on thermodynamic calculations $[2]$.

As reported by several authors [4-7], after conventional quenching, the microstructure is composed of 1) fresh martensite, 2) a mixture of the $\mathrm{M}_{2} \mathrm{C}$ and $\mathrm{M}_{23} \mathrm{C}_{6}$ carbides, and 3) retained austenite. The latter can decompose into ferrite and cementite during subsequent tempering between $573 \mathrm{~K}$ and $773 \mathrm{~K}$ thereby affecting the mechanical properties of the alloy [3]. Also, in a recent study [8] the present authors reported that conventional hardening treatment of this steel does not result in martensitic microstructure and instead a mostly bainitic microstructure was obtained. Therefore, higher cooling rates as well as very low cooling temperatures are required for complete martensitic transformation to take place in AISI D2 steel.

The effect of cryogenic treatment on microstructure evolution, wear, and mechanical properties of Fe-C steel, tool steels, and specifically AISI D2 tool steel has been previously reported by many researchers [10-21]. The temperature ranges studied by researchers varies from $223 \mathrm{~K}$ to $77 \mathrm{~K}$ and depending on the investigated temperature interval, the denominations are different: 'cold treatment' for the interval $223 \mathrm{~K}-193 \mathrm{~K}$; 'shallow cryogenic treatment' for the $193 \mathrm{~K}-113$ 
$\mathrm{K}$ interval; and 'deep cryogenic treatment' for the $113 \mathrm{~K}-77 \mathrm{~K}$ interval. Preciado and Pellizzari [10], Olia et al. [12], and Das et al. [19, 21] have presented the most recent studies on the influence of cryogenic treatment and subsequent tempering on the sequence of precipitation of temper carbides and the evolution of mechanical and wear properties. However, in spite of the extensive amount of work, little information is available on martensite's characteristics and the kinetics of martensitic transformation during direct cooling to $173 \mathrm{~K}$ (shallow cryogenic temperature).

In the present research, the above aspects are studied using a combination of high resolution dilatometer, scanning electron microscope (SEM), and transmission electron microscope (TEM). The obtained results are correlated with the existing models for martensitic transformation in steels and an equation is proposed which better describes the phase transformation for AISI D2 steel.

\section{Mathematical analysis of dilatometry curves}

Dilatometry is a powerful in-situ method to monitor solid state phase transformations characterized by changes in the lattice structure (e.g. austenite to martensite transformation) which are translated into variation of the specific volume of the specimen [22, 23]. However, it is not always possible to detect with precision the amount of volume change during the transformation as well as transformation start and finish points. High resolution dilatometry permits for precise temperature control and recording of nanometric volumes changes thereby allowing for the detection of the early stages of phase transformations as well as differentiation of superimposed processes which cannot be revealed with conventional dilatometry equipment. The transformation start and finish temperatures are often determined using tangent line method [24] and first derivative or off-set methods [25]. In order to estimate the volume changes during 
the martensitic transformation, mathematical equations are used to fit the experimental dilatation curves [26]. Yamamoto [26] proposed a model in which the total volume change during martensitic transformation is dependent on the sum of three variables: (1) shrinkage of the retained austenite, (2) shrinkage of newly formed martensite, and (3) the expansion as a result of austenite-martensite transformation. This model is briefly described in equations (1) and (2) [26].

$$
\begin{gathered}
d_{i+1}=d_{i}-\left(f_{m} \alpha_{m}+f_{\gamma} \alpha_{\gamma}\right) \Delta T \\
E_{i+1}=d_{i+1}+\varepsilon_{\gamma-m} f_{m}
\end{gathered}
$$

, where $i$ shows i-th experimental point, $d$ the shrinkage due to expansion coefficient, $E$ the total dilatation at a $i$-th temperature, $\alpha_{m}$ the expansion coefficient of martensite, $\alpha_{\gamma}$ the expansion coefficient of austenite, $\varepsilon_{\gamma-m}$ the strain due to lattice volume differences between austenite and martensite, and $f_{m}$ the volume fraction of martensite stated with Koistinen and Marburger (K-M) equation [27] (Eq.3).

$$
f_{m}=1-\exp \left[-b\left(M_{s}-T\right)\right]
$$

In Eq.3, $M_{s}$ is martensite start temperature; $b$ is a material constant varying with chemical composition and T is cooling start temperature [28]. Qui et al. [28] have reassessed Yamamoto's model and reported several inconsistencies including: no unique $f_{m}$ for a given material, problems regarding the measurements of $\alpha_{m}$, difficulty in finding unique $b, M_{s}, \varepsilon_{\gamma-m}$, and errors between calculated and experimental results [26]. Equations (1) and (2) were reformulated as shown in Eq. (4) where it can be seen that five variables need to be determined in order to obtain an accurate fitting of the dilatation results [28].

$$
E=E_{0}+\left(\varepsilon_{\gamma-m}-\alpha_{m} M_{s}-\left(\alpha_{\gamma}-\alpha_{m}\right) / b\right)+\alpha_{m} T+\left(\left(\alpha_{\gamma}-\alpha_{m}\right) / b-\varepsilon_{\gamma-m}\right) \cdot \exp \left(-b\left(M_{s}-T\right)\right.
$$


In the above equation $E$ represents the total dilatation during transformation and $E_{0}$ corresponds to the dilatation at $M_{s}$ temperature. In the present work the approach proposed by Qui et al. [28] was used to obtain the best fit for the dilatometry curves obtained during the experiments. On the basis of this analysis a more simplified equation is proposed (Eq. (5)) and it is also demonstrated that $b$ is not a constant value but rather varies as a function of the cooling rate.

$$
E=E_{0}-3.83 \times 10^{-6}+\alpha_{m} T-4.235 \times 10^{-3}\left(\exp \left(-b\left(M_{s}-T\right)\right)\right)
$$

\section{Materials and methods}

The as-received AISI D2 material was $15 \mathrm{~mm}$ thick rolled sheet with the nominal composition of C 1.54 - Si 0.33 - Mn 0.32 - Cr 11.88- Mo 0.76 - V 0.75- P 0.008- S 0.008(wt pct). Samples were cut into $10 \mathrm{~mm}$ height and $4 \mathrm{~mm}$ diameter cylinders with their height parallel to the rolling direction. High resolution BÄHR DIL 805 A/D dilatometer with a $50 \mathrm{~nm}$ resolution at high speed cooling rates was used to carry out the experiments. Samples were heated to $1303 \mathrm{~K}$ and maintained for 1200 seconds followed by continuous cooling to $173 \mathrm{~K}$ at $10 \mathrm{Ks}^{-1}$ or $50 \mathrm{Ks}^{-1}$.

The $50 \mathrm{Ks}^{-1}$ cooling rate was selected in order to avoid any carbide precipitation before the start of the martensitic transformation and also to insure an almost fully martensitic structure upon quenching. Finally, the samples were brought to room temperature with a heating rate of $10 \mathrm{Ks}^{-1}$. In order to examine the kinetics of austenite to martensite transformation a significantly lower cooling rate, $10 \mathrm{Ks}^{-1}$, was used. In order to avoid any oxidation and decarburization, the heat treatment cycle was conducted in vacuum environment. An etchant with the following composition $40 \mathrm{~g} \mathrm{NaOH}+60 \mathrm{~g} \mathrm{H}_{2} \mathrm{O}+15 \mathrm{~g} \mathrm{NaNO}_{3}$ initially proposed by Gouné et al. [29] was modified and successfully used for revealing martensite. Hitachi-TM3030 SEM and X-ray diffraction diagrams (XRD) were used for microstructural studies. The carbides count was

calculated using the $\mathrm{MIP}^{\circledR}$ image analysis software [30]. For TEM studies, the sample cooled at 
rate of $50 \mathrm{Ks}^{-1}$ was prepared by precision ion polishing (PIPS). Thin foils were then examined using an FEI Tecnai $\mathrm{G}^{2}$ F20 TEM operated at $200 \mathrm{kV}$.

\section{Results}

\section{Dilatometry analysis}

The dilatation curves versus undercooling are presented in Figs.1a-d and 2a-d for cooling rates of $10 \mathrm{Ks}^{-1}$ and $50 \mathrm{Ks}^{-1}$, respectively. The contraction curve showed parabolic behavior for the 10 K.s ${ }^{-1}$ cooling rate (Fig.1a) while almost linear behavior was observed for the $50 \mathrm{Ks}^{-1}$ cooling rate (Fig.2a) before the start of martensitic transformation. Splitting phenomena was observed around $480 \mathrm{~K}$ for the slow cooling rate (Fig.1a) and $450 \mathrm{~K}$ for the fast one (Fig.2a). De Andrés et al. [31] and Caballero et al. [32] have studied this effect in detail and related it to the presence of concentration gradients in the austenite, due to partial or total dissolution of carbides upon austenitization. Considering the similarities between the results obtained by the present investigation and those reported by the above authors, the observed splitting phenomena is also associated with the presence of chemical heterogeneities in the austenite which are revealed by the high resolution dilatometer. It is worth noting that the sudden change in dilatation observed around $300 \mathrm{~K}$ in both conditions is due to the introduction of liquid nitrogen into the test chamber and is not related to any microstructural phenomenon.

Figs. $1 \mathrm{~b}$ and $2 \mathrm{~b}$ show comparison between experimental results (black curve) and modeled data (red curve). The occurrence of martensitic transformation from $M_{s}$ to $173 \mathrm{~K}$ can be observed in both cases. Two distinct behaviors are distinguishable: 1) regular behavior consisting of expansion starting at $M_{s}$ and reaching a maximum value around $325 \mathrm{~K}$; 2) an atypical behavior below $325 \mathrm{~K}$, where either another expansion is observed (Fig.1b - black curve) or the normal contraction expected at these low temperatures does not occur (Fig.2b-black curve). The second 
expansion in dilatation curve, as indicated in Fig.1b, has been also observed by Wierszyllowski [33] and related to activation of a second martensitic transformation taking place below $273 \mathrm{~K}$. Using Eq. (5) and the data reported in Table 1, best fits were obtained for dilatometry curves and the results are shown in Figs. $1 \mathrm{~b}$ and $2 \mathrm{~b}$ (red curves) for the slow and fast cooling rates, respectively. Based on the above analysis, it can be said that the proposed model predicts relatively well the dilatation behavior until $325 \mathrm{~K}$; however, below this temperature, deviation occurs between experimental results and the predicted ones which may be due to secondary martensitic transformation or abnormal contraction between $325 \mathrm{~K}$ and173 K.

The influence of undercooling on the volume fraction of martensite is shown in part c of Figs.1 and 2. The above data was obtained by finding the values of $M_{s}$ and $b$ from Eq.5 and using K-M equation. It can be said that the regular behavior ends once 78 percent of austenite is transformed to martensite for the cooling rate of $10 \mathrm{Ks}^{-1}$ (Fig.1c) while for the cooling rate of $50 \mathrm{Ks}^{-1}$ it finishes when 85 percent of austenite is transformed to martensite (Fig.2c). Thus, the remaining austenite (22\% and $15 \%$ respectively) will undergo atypical behavior until the end of the process. The proposed model predicts the presence of $1.5 \%$ and $3 \%$ retained austenite, in the final microstructure, for fast cooled and slow cooled samples, respectively.

The high resolution dilatometer made also possible to screen small variations in expansion or contraction during soaking at austenitizing temperature. For example, Fig.1d (red dashed lines) shows a value of $0.09 \%$ for compressive strain in the case of $10 \mathrm{Ks}^{-1}$ cooling rate while this value was $0.02 \%$ in the case of $50 \mathrm{Ks}^{-1}$ cooling rate (Fig.2d, red dashed lines,). The occurrence of non-uniform strain during austenitization, as illustrated in Figures 1d and 2d, was observed repeatedly for many other test conditions carried out by the authors. The detailed quantification of this effect and its impact on the kinetics of martensitic transformation is presently carried out 
by the authors and will be the subject of a separate communication. In the context of the present paper, it can be said that chemical heterogeneity in the microstructure or stabilization of retained austenite could be possible causes of such effect. Indeed, carbides in AISI D2 tool steel have smaller coefficient of thermal expansion than the parent phase, thereby affecting the normal dilatation of the matrix and generating anisotropic strains [34]. During austenitization, due to the holding at high temperature, the austenite is relaxed from these strains; in contrast because of the partial dissolution of carbides, the strength of austenite is increased [34]. It is relevant to mention that slower cooling rates could also contribute to retained austenite stabilization and therefore to the occurrence of the atypical behavior. This is illustrated in Figs. 1c and 2c, where it can be seen that martensite fraction in slow cooled sample is smaller than in the fast cooled one.

Finally, it is important to note that the results obtained in the present investigation reveal a dependency of the value of the 'constant' $b$ on the cooling rate employed during testing. While the dependency of $\mathrm{b}$ on steel composition has been previously reported [28, 35], to the knowledge of the authors, this is the first time that its variation with cooling rate is demonstrated.

\section{Microstructural analysis}

Fig.3 shows the SEM micrographs of the microstructure obtained after cooling at the rate of 10 $\mathrm{Ks}^{-1}(\mathrm{a})$ and $50 \mathrm{Ks}^{-1}(\mathrm{~b})$. They both show similar features such as plate-like martensite, large primary carbides, and fine secondary carbides (details brought in Introduction); no trace of grain boundaries is observed which confirms similar chemical composition between the product (martensite) and the parent phase (austenite). X-ray diffraction analysis did not show austenite peaks for both heat treatment conditions. In order to investigate possible carbide precipitation before the start of transformation for the lower cooling rate $\left(10 \mathrm{Ks}^{-1}\right)$, back scattered electron (BSE) detector was used. The influence of cooling rate on the presence of very fine carbides 
(below $1 \mathrm{~m}$ ) is shown in Fig.4a-c. A higher population of carbides with average diameter below $1 \mathrm{~m}$ is observed in the samples cooled at $10 \mathrm{Ks}^{-1}$ (Fig.4c). XRD diagrams for both conditions are shown in Fig. $4 \mathrm{~d}$. The $\mathrm{M}_{7} \mathrm{C}_{3}$ main XRD peak is located at 2-theta $\approx 44^{\circ}$ with $\mathrm{M}$ being mostly $\mathrm{Cr}$ and Fe. The $M_{7} C_{3}$ peak intensity is higher for slow cooled sample corresponding to higher volume fraction of these carbides. In the figure, the (110) martensite peak located at $44.5^{\circ}$ is also shown to distinguish it from the $\mathrm{M}_{7} \mathrm{C}_{3}$ peak. It is worth mentioning that, as reported by several authors $[2,6,7]$ submicron size secondary carbides precipitate in AISI D2 steel during hot forming and will be retained after quenching. However, they can't be detected readily by X-ray diffraction due to their small sizes and TEM is needed to reveal them [6].

The above findings confirm that the splitting phenomenon observed in the dilatometry curve of the slow cooled sample (Fig.1a) corresponds to carbide precipitation (carbon-depleted austenite) while the splitting observed in the dilatometry curve of the fast cooled sample (Fig. 2a) is related to the occurrence of transformation in carbon-rich austenite. The obtained results are in agreement with those reported by other authors [30, 31].

In order to study the detailed morphology of martensite, TEM observation was carried out on the sample cooled at $50 \mathrm{Ks}^{-1}$. As shown in Fig. 5a-b, the microstructure is mainly composed of plate martensite (Fig.5a); however, a noticeable amount of lath type morphology is also observed (Fig.5.b). Using the Thermo-Calc software`s TCFE7 database and methodology provided in reference [36], the carbon content of austenite at $1303 \mathrm{~K}$ was estimated to be about 0.52 (wt $\%$ ). Considering that low $M_{s}$ temperature promotes the formation of plate martensite in expense of lath type [37], it is reasonable to observe a mixed morphology of lath and plate martensite. More detailed discussion on the factors controlling martensite morphology will be provided in the discussion section. 
In addition to the observed plate and lath martensite, nano sized twins were also observed in several areas of the examined samples, as shown in the bright-field TEM images in Fig.6 a-d. A series of highly dense internal transformation nano-twins with a thickness of $10 \mathrm{~nm}$ are accommodated in the areas expanding over $600 \mathrm{~nm}$ (Fig.6a-c). Selected area diffraction (SAD) pattern, taken from area shown by yellow circle in Fig.6c, is presented in Fig.6d indicating that the nano-twins are located in 112 planes and the relationship between the matrix and the twins. The obtained results are in agreement with those reported by other authors [37-39] on Fe-Cr-C steel where the same type of orientation was observed between the matrix and the nano-twins. It has been reported that internal martensite twins can be considered as transformation twins if they meet the symmetry requirements otherwise they are just demonstrations of adjustment effects [40]. In the present investigation, it was found that (Fig 6d) the twin plane is always a plane of mirror symmetry with respect to the austenite indicating that the observed nano-twins in the microstructure are internal transformation twins produced as a result of the cryogenic cooling.

\section{Discussion}

\section{Kinetics of martensite formation}

The Koistinen and Marburger equation (Eq.3) [27] is often used to describe the extent of transformation as function of temperature. In this equation, $b$ is a rate parameter which is often considered as dependent on the steel composition and can be extracted from empirical equations [35]. In some cases, this parameter has also been considered as $\mathrm{K}-\mathrm{M}$ original constant value which has been suggested to be about $0.011 \mathrm{~K}^{-1}$ for plain carbon steel [27]. However, using empirical equation described in ref. [35], it was not possible to predict a suitable value for $b$ to be able to obtain the best fit for the obtained results because the empirical equation has been developed for a certain compositional range and as such has limited applicability. On the other 
hand, using a constant value for $b$ as provided in reference [27] it was not possible to obtain an acceptable fit for the experimental results. In the present investigation it was found that the equation proposed by Qui et al. [28] allows for a more accurate prediction of the fraction transformed and the influence of chemical composition and cooling rate are considered in the estimation of the rate parameter b. Fig.7 depicts the effect of higher cooling rate on the value of $b$ obtained from Eq.5.

Additionally, parameter $b$ can be defined approximately in terms of the linear relation between chemical driving force of transformation with the number of new martensite plates formed per unit volume as shown below [41, 42].

$$
b=-\bar{\vartheta} \phi(d(\Delta G) / d T)(6)
$$

where $\bar{\vartheta}$ is the average volume of the newly formed martensite plates caused by temperature variation $d T, \phi$ is a proportionality constant, $\Delta G$ is the volume free energy change accompanying transformation and $T$ is the temperature. In this research, two different values for $b$ have been found as a result of change in cooling rate (see Table 1). The chemical driving force $\left(\Delta G^{\gamma \rightarrow \alpha}\right)$ of austenite to martensite (ferrite) transformation for AISI D2 tool steel can be extracted from Thermo-Calc database TCFE7 (Fig.8).

If the values of chemical driving force between $M_{s}$ temperature and $325 \mathrm{~K}$, where regular behavior ends (by model), are divided by undercooling (with considering same value for $\phi$ ); the average volume of martensite phase can be estimated as indicated below.

$$
\begin{aligned}
& b_{10 K s^{-1}}=0.0128=-\bar{\vartheta} \varphi\left(\frac{\Delta G_{325 K}-\Delta G_{M_{s}=444 K}}{325-444}\right)=-\bar{\vartheta} \varphi\left(\frac{-3470+2570}{-119}\right) \Rightarrow \bar{\vartheta}=0.00169 \varphi \\
& b_{50 K^{-1}}=0.0156=-\bar{\vartheta} \varphi\left(\frac{\Delta G_{325 K}-\Delta G_{M_{s}=450 K}}{325-450}\right)=-\bar{\vartheta} \varphi\left(\frac{-3470+2547}{-125}\right) \Rightarrow \bar{\vartheta}=0.00211 \varphi
\end{aligned}
$$


The above results indicate that higher average volume fraction of martensite is obtained for higher $b$ value which is in agreement with the results obtained in Fig. 7 using Eq. 5 with a variable $b$ value.

\section{Factors controlling martensite morphology}

In Fe-C-Cr steels, lath martensite forms at higher $M_{s}$ temperature compared to plate martensite [37]. The $M_{s}$ temperature calculated from Eq.5 for the first part of the dilatation diagram did not show considerable changes (between $444 \mathrm{~K}$ and $450 \mathrm{~K}$ ) by increasing the cooling rate from 10 to $50\left(\mathrm{Ks}^{-1}\right)$ indicating that the $M_{s}$ temperature of AISI D2 steel is not affected by cooling rates in this range. However, significant changes in $M_{s}$ temperature causing morphology changes from lath to plate type have been reported where very high cooling rates, above $6000 \mathrm{Ks}^{-1}$, were used in ferrous alloys [43].

The strength of austenite and martensite can also affect the morphology of martensite [44]. The active habit plane of martensite can be determined as a function of the resistance of austenite and martensite to dislocations motion [44]. The results obtained in this study revealed the presence of both lath and plate morphologies in the microstructure (Fig.5 a-b). Also, as indicated in Figs.1d and $2 \mathrm{~d}$, a contractive strain is observed during soaking at austenitizing temperature. The source of this strain can be attributed to chemical inhomogeneity caused by the dissolution of carbides or the stabilization of retained austenite because of the slow cooling [23, 34]. The presence of the contraction observed in this study indicates that part of the austenite phase has a higher strength level. Such difference in strength level determines the type of habit plane that will be activated and as a result the martensite morphology which will be formed. In the present investigation plate shaped martensite with $\{225\}_{\gamma}$ habit plane and highly dislocated platelets or lath martensite 
with $\{111\}_{\gamma}$ habit plane was identified. The above results are in agreement with those reported by other authors on the preferred habit planes for these types of martensite [37, 44].

It has been reported that $\{225\}$ martensite does not have clearly defined midrib while it could be internally twinned [43]. The results obtained in the present investigation are in agreement with the above reports as no trace of midrib was observed in TEM micrographs (Fig.5a-b) and internal nano-twins were present in the microstructure (Fig.6a-d). It is well known that low $M_{s}$ temperatures promote the formation of twins [45]. For the investigated alloy, it was calculated that in the range $325 \mathrm{~K}-173 \mathrm{~K}, 15 \%$ to $22 \%$ of austenite transforms to martensite, respectively (Figs. 1c and 2c). It is therefore reasonable to assume that the formation of internal nano-twins in this temperature range is due to austenite transformation.

Martensitic transformation is always accompanied with plastic deformation and the dominant deformation mode in austenite could be modified by changes in critical resolved shear stress [34, 45]. The presence of a significant amount of nano-twins observed on the martensite produced during cooling indicates that, under these conditions, the critical resolved shear stress for twinning is lower than the one for slip and therefore austenite to martensite transformation is promoted in expense of slip.

\section{Conclusions}

In this research, martensitic transformation of AISI D2 tool steel via continuous cooling to $173 \mathrm{~K}$ was investigated. The following main conclusion can be drawn from this investigation:

1. Two distinct regions were identified in the dilatometry diagrams: a) regular behavior where expansion in the curve starts at $M_{s}$ and reaches the maximum around $325 \mathrm{~K}$; and b) an atypical behavior below $325 \mathrm{~K}$ where the dilatation does not follow normal contraction or another expansion occurs. 
2. Kinetics study showed $15 \%$ to $22 \%$ of martensite formation, depending on the cooling rate, occurs between room temperature and the cryogenic temperature with only 1.5 to 3 $\%$ of non-transformed austenite in the final microstructure.

3. Microstructural analysis showed the concomitant presence of lath and plate morphologies as well as nano-twins.

4. The occurrence of nano-twins was related to the changes in the deformation mode of austenite when austenite undergoes martensitic transformation between room temperature and cryogenic temperature.

5. $M_{s}$ temperature, microstructural heterogeneity, and strength of austenite were found as effective factors influencing the morphology of martensite.

\section{Acknowledgements}

The authors would like to thank the National Sciences and Engineering Research Council of Canada (NSERC) for their support and financial contribution through the ENGAGE and ENGAGE plus programs. The authors also appreciate the collaboration of DK SPEC Inc. for providing experimental materials, support from CanmetMATERIALS in the framework of RIEM program for dilatometry experiments, Hitachi Canada for privileged access to advanced microscopy facilities.

\section{References}

[1] Arai T et al. (1991) ASM Handbook, Heat Treating, ASM International, USA.

[2] Bombac D, Fazarinc M, Saha Podder A, Kugler G (2013) Study of carbide evolution during thermomechanical processing of AISI D2 tool steel. JMEPEG 22: 742-747.

[3] Speich GR, Leslie WC (1972) tempering of steel, Metall. Trans. 3-5: 1043-1054.

[4] da Silva Farina PF, Barbosa CA, Goldenstein H (2011) Microstructural characterization of an AISI D2 tool steel submitted to cryogenic treatment. Journal of ASTM International 8-5: 1-8. 
[5] Das D, Dutta AK, Ray KK (2009) Influence of varied cryotreatment on the wear behavior of AISI D2 steel. Wear 266:297-309.

[6] Tyshchenko AI, Theisen W, Oppenkowski A, Siebert S, Razumov ON, Skoblik AP, Sirosh VA, Petrov YN, Gavriljuk VG (2010) Low-temperature martensitic transformation and deep cryogenic treatment of a tool steel. Mater Sci and Eng A 527: 7027-7039

[7] Gavriljuk VG, Sirosh VA, Petrov YN, Tyshchenko AI, Theisen W, Kortmann A (2014) Carbide precipitation during tempering of a tool steel subjected to deep cryogenic treatment. Metall Mater Trans A 45(3): 2453-2465.

[8] Ghasemi Nanesa H, Jahazi M (2015) Alternative phase transformation path in cryogenically treated AISI D2 tool steel. Mater Sci and Eng A. accepted, in press.

[9] Gavriljuk VG, Theisen W, Sirosh VV, Polshin EV, Kortmann A, Mogilny GS, Petrov N, Tarusin YV (2013) Low-temperature martensitic transformation in tool steels in relation to their deep cryogenic treatment, Acta Mater 61: 1705-1715

[10] Preciado M, Pellizzari M (2014) Influence of deep cryogenic treatment on the thermal decomposition of $\mathrm{Fe}-\mathrm{C}$ martensite.

[11] Singh SG, Singh J, Singh R, Singh H (2012) Metallurgical principles of cryogenically treated tool Steels-a review on the current state of science, J Adv Manuf Technol 54: 59-82.

[12] Oila A, Lung C, Bull S (2014) Elastic properties of eta carbide $\left(\eta-\mathrm{Fe}_{2} \mathrm{C}\right)$ from ab initio calculations: application to cryogenically treated gear steel. J Mater Sci 49:2383-2390.

[13] Rhyim YM, Han SH, Na YS, Lee JH (2006) Effect of deep cryogenic treatment on carbide precipitation and mechanical properties of tool steel, Steel Solid State Phenom 118: 9-14.

[14] Collins DN, Dormer J (1997) Deep cryogenic treatment of a D2 cold-worked tool steel. J Heat Treat Met 3: 71-74.

[15] Gulyaev AP (1937) Improved methods of heat treating high speed steels to improve the cutting properties, Metallurgy 12: 65-70. 
[16] Das D, Dutta AK, Ray KK (2009) Influence of temperature of sub-zero treatments on the wear behaviour of die steel. Wear 267: 1371-1380.

[17] Das D, Dutta A, Ray KK (2010) Sub-zero treatments of AISI D2 steel: Part I. Microstructure and hardness. Mater Sci Eng A527: 2182-2193.

[18] Huallpa EA, Sánchez JC, Padovese LR, Goldenstein H (2013) Determining $\mathbf{M}_{\mathrm{s}}$ temperature on a AISI D2 cold work tool steel using magnetic Barkhausen noise, J Alloy Compd 577: S726-S730.

[19] Das D, Ray KK (2012) Structure-property correlation of sub-zero treated AISI D2 steel. Mater Sci Eng A 541: 45-60.

[20] Das D, Dutta AK, Ray KK (2009) On the refinement of carbide precipitates by cryotreatment in AISI D2 steel. Phil Mag 89- 1: 55-76.

[21] Das D, Dutta AK, Ray KK (2010) Structure-Property Correlation of Cryotreated AISI D2 Steel. Advanced Materials Research 117: 49-54.

[22] Garcia de Andrés C, Caballero FG, Capdevila C, Alvarez LF(2002) Application of dilatometric analysis to the study of solid-solid phase transformations in steels, Mater Charact 48: 101-111.

[23] Yu HY (1997) A new model for the volume fraction of martensitic transformations, Metall Mater Trans 28A: 2499-2506.

[24] Motyca P, Kövér M (2012) Evaluation Methods of Dilatometer Curves of Phase Transformations, COMAT 2012, conference proceedings, Parkhotel Plzen, Czech Republic, EU Czech Republic.

[25] Yang HS, Bhadeshia HKDH (2007) Uncertainties in dilatometric determination of martensite start temperature, Mater Sci and Tech 23-5: 556-560.

[26] Yamamoto J, Meguro S, Muramatsu Y, Hayakawa N, Hiraoka K (2007) analysis of martensite transformation behavior in welded joints of low transformation-temperature materials, Q J Jpn Weld Soc 25: $560-568$.

[27] Koistinen DP, Marburger RE (1959) A general equation prescribing the extent of the austenitemartensite transformation in pure iron-carbon alloys and plain carbon steels, Acta Metall 7: 59-60. 
[28] Qiu H, Qi J, Yin F, Hiraoka K (2009) Determining of parameters for fitting the dilatation curve of austenite-martensite transformation in Cr-Ni steels, ISIJ Int 49-1: 146-148.

[29] Gouné, Bouaziz O, Allain S, Zhu K, Takahashi M (2012) Kinetics of bainite transformation in heterogeneous microstructures, Mater Lett 67-1:187-189.

[30] Nahamin Pardazan Asia, 〈http://en.metsofts.ir/〉, Iran, 2014.

[31] García de Andrés C, Jiménez JA, Álvarez LF (1996) splitting phenomena occurring in the martensitic transformation of $\mathrm{Cr} 13$ and CrMoV14 stainless steels in the absence of carbide precipitation, Metall Mater Trans 27A-7: 1799-1805.

[32] Caballero FG, Alvarez LF, Capdevila C, Garcıa de Andrés C (2003) The origin of splitting phenomena in the martensitic transformation of stainless steels, Scripta Mater 49-4: 315-320.

[33] Wierszyllowski IA (1997) Martensitic transformation of austenite below $273 \mathrm{~K}$. dilatometric and magnetic studies, J Phys IV France 07: C5-417-C5-422.

[34] Wei J, Kessler O, Hunkel M, Hoffmann F, Mayr P (2004) Anisotropic phase transformation strain in forged D2 tool steel, Mater Sci and Technol 20: 909-914.

[35] Bohemen SMC van (2012) Bainite and martensite start temperature calculated with exponential carbon dependence, Mater Sci Technol 28: 487-495.

[36] Yaso M, Morito S, Ohba T, Kubota K (2008) Microstructure of martensite in Fe-C-Cr steel, Mater Sci Eng A 481-482: 770-773.

[37] Umemoto M, Yoshitake E, Tamura I (1983) The morphology of martensite in Fe-C, Fe-Ni-C and FeCr-C alloys, J Mater Sci 18: 2893-2904.

[38] Lee HY, Yen HW, Chang HT, Yang JR (2010) Substructures of martensite in Fe-1C-17Cr stainless steel, Scripta Mater 62- 9: 670-673.

[39] Das D, Ray KK (2012) On the mechanism of wear resistance enhancement of tool steels by deep cryogenic treatment. Phil Mag Lett 92-6: 295-303. 
[40] Bhadeshia HKDH, Edmonds DV (1979) A direct analysis of twinning in a low alloy martensite, Phase Transformations, York Conference, the Institution of Metallurgists, 2-11: IV-4 to IV-8.

[41] Bhadeshia HKDH (1982) An aspect of the nucleation of "burst" martensite in steels, J Mater Sci 17: 383-386.

[42] Magee CL (1970) The nucleation of martensite: in: H. I. Aaronson, V. F. Zackay (Eds.), Phase transformations: ASM International, Materials Park, Ohio, USA: 115-156.

[43] Donachie SJ, Ansell GS (1975) The effect of quench rate on the properties and morphology of ferrous martensite, Metall Trans 6A: 1863-1875.

[44] Davies RG, Magee CL (1971) Influence of austenite and martensite strength on martensite morphology, Metall Trans 2: 1939-1947.

[45] Johari O, Thomas G (1965) Factors determining twinning in martensite, Acta Metall 13: 1211-1212. 
Figures captions

Fig.1 (a) Dilatation diagram during cooling at the rate of $10 \mathrm{Ks}^{-1}$ depicting the start of martensitic transformation $\left(M_{s}\right)$, (b) curve fitting results based on Eq.5 in comparison with experimental results in the region where tarnsformation occurs in part a, (c) change in volume fraction of martensite versus under cooling calculated by Eq.5, (d) evolution of compressive strain during holding time at austenitization temeprature. The maximum compression strain was obtained by subtarcting the highest expansion value from the value right before the start of cooling (range is shown by red dashed lines).

Fig.2 (a) Dilatation diagram during cooling at the rate of $50 \mathrm{Ks}^{-1}$ depicting the start of martensitic transformation $\left(M_{s}\right)$, (b) curve fitting results based on Eq.5 in comparison with experimental results in the region where tarnsformation occurs in part a, (c) change in volume fraction of martensite versus under cooling calculated by Eq.5, (d) evolution of compressive strain during holding time at austenitization temeprature. The maximum compression strain was obtained by subtarcting the highest expansion value from the value right before the start of cooling (range is shown by red dashed lines).

Fig.3 (a) SEM micrograph of the alloy cooled at the rate of $10 \mathrm{Ks}^{-1}$, (b) SEM micrograph of the alloy cooled at the rate of $50 \mathrm{Ks}^{-1}$ (microstructure features: primary large carbides and secondary carbides; no trace of grain boundaries).

Fig.4 The effect of higher cooling rate on the suppression of carbide precipitation during cooling (a) BSESEM micrograph from microstructure of the alloyed cooled at the rate of $10 \mathrm{Ks}^{-1}(\mathrm{~b})$ BSE-SEM micrograph from microstructure of the alloyed cooled at the rate of $50 \mathrm{Ks}^{-1}$, (c) diagram showing the number of carbides with size less than $1 \mathrm{~m}$ for conditions in parts (a) and (b), (d) XRD diagrams showing (421) peak of $\mathrm{M}_{7} \mathrm{C}_{3}$ carbide and (111) of marteniste (overlap is due to very close diffraction angles).

Fig.5 Morphology of martensite as result of cooling at the rate of $50 \mathrm{Ks}^{-1}$ (a) Bright-field TEM image of partly plate type martensite (b) bright-field TEM image of lath type martensite.

Fig.6 (a) nano-twins (circled area) in the substructure of the alloy cooled at the rate of $50 \mathrm{Ks}^{-1}$ (b) higher magnification of the same area showing high density of dislocation in smaller bands ( $\approx 10 \mathrm{~nm}$ thick) (c) very high magnification showing one nano-twin (yellow circle shows the area over which SAD pattern was taken, (d) corresponding analysis of SAD pattern.

Fig.7 Effect of cooling rate on the resulted b factor from Eq.5.

Fig.8 Chemical Gibbs free energy changes during diffusionless transformation from austenite to martensite (ferrite) extracted from Thermo-Calc database TCFE7, given for the composition of austenite at $1303 \mathrm{~K}$. 
Table caption

Table 1 Data used for curve fitting for both $10 \mathrm{Ks}^{-1}$ and $50 \mathrm{Ks}^{-1}$ cooling rates 


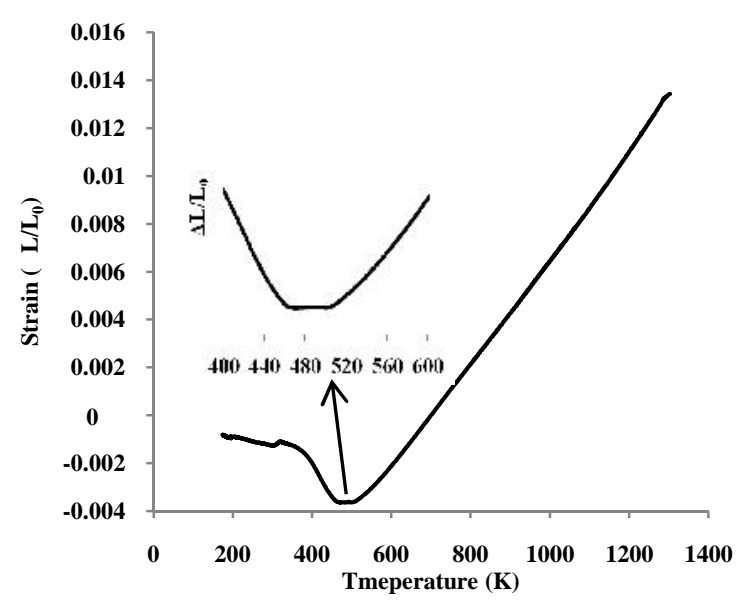

(a)

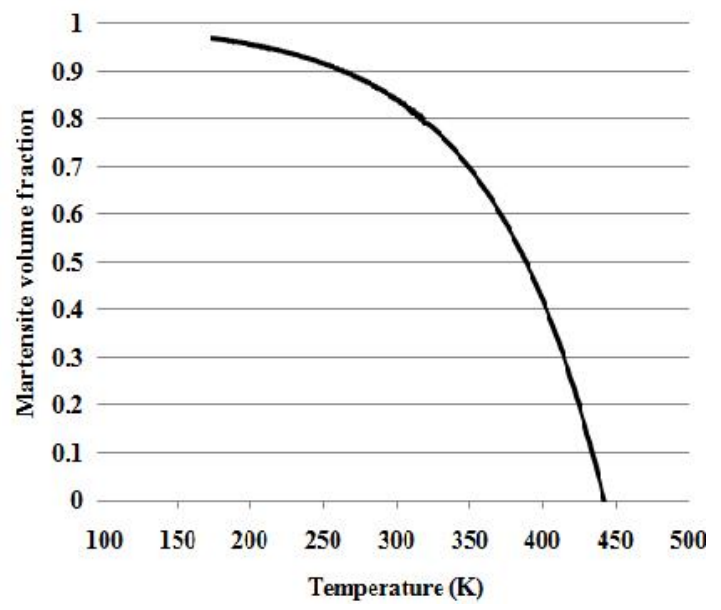

(c)

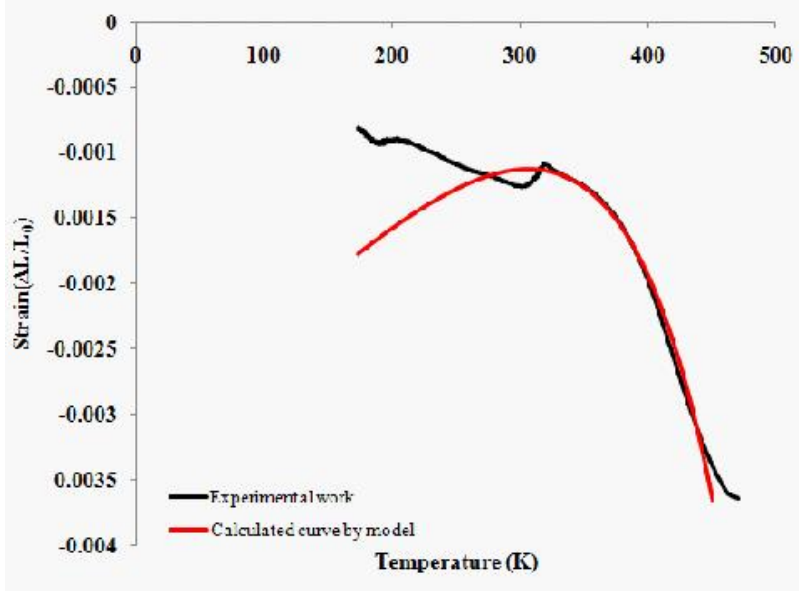

(b)

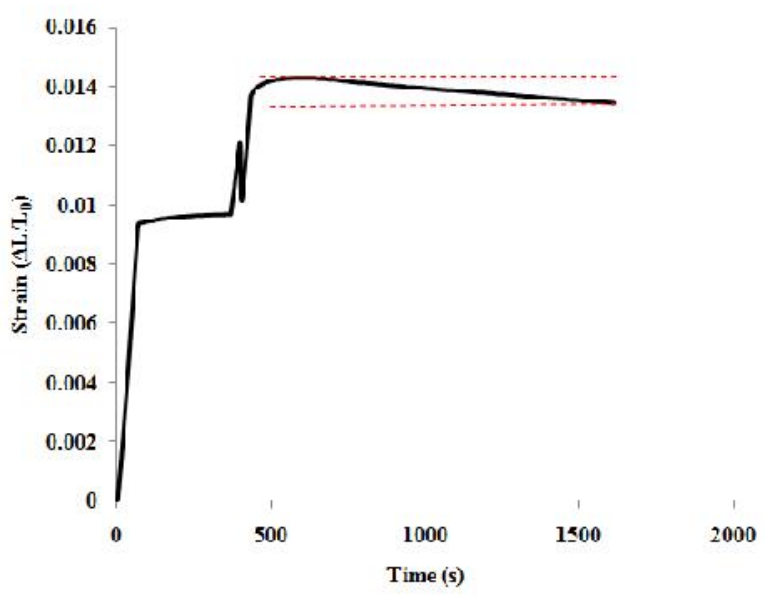

(d)

Fig.1 


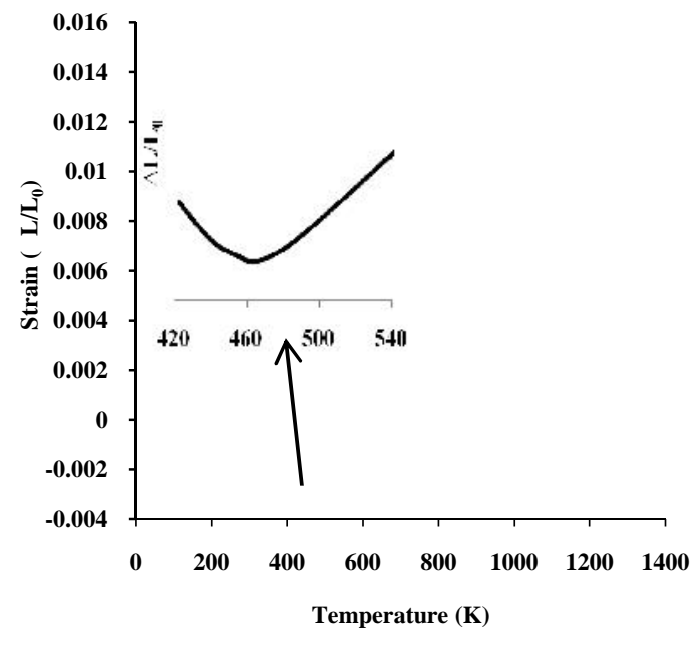

(a)

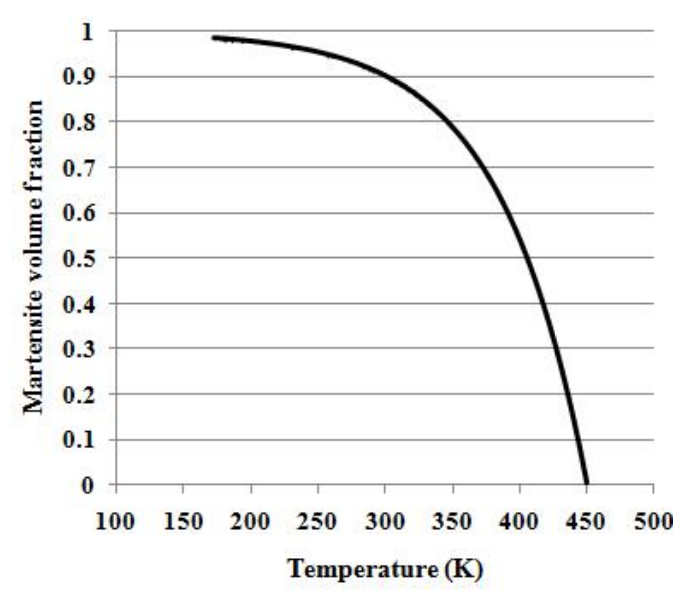

(c)

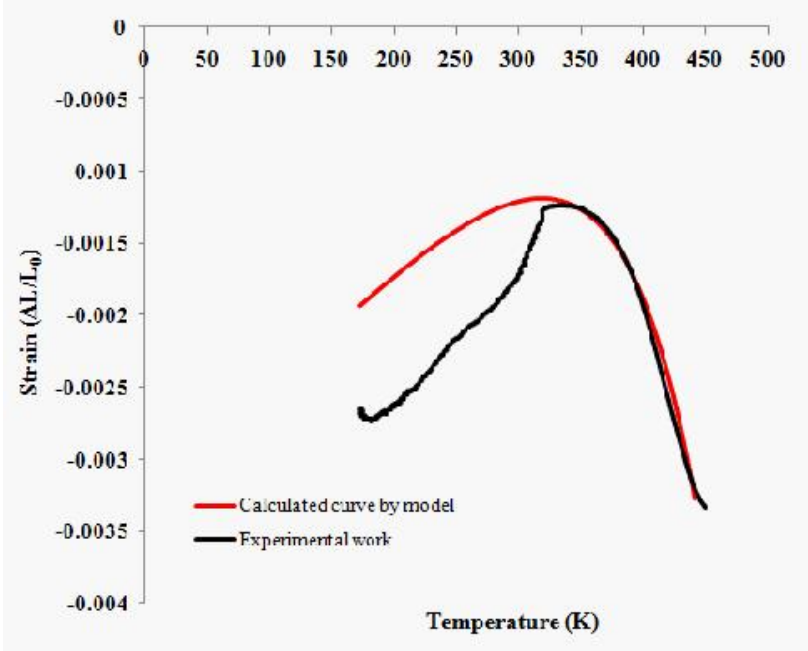

(b)

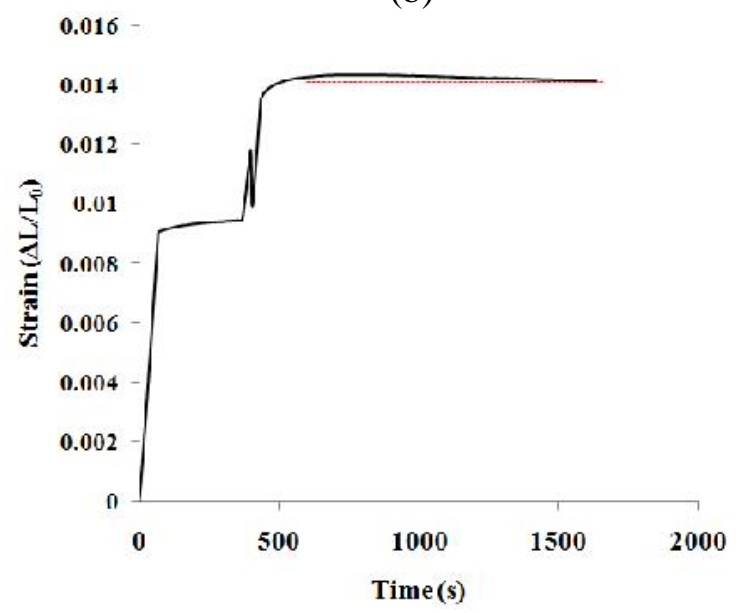

(d)

Fig.2 


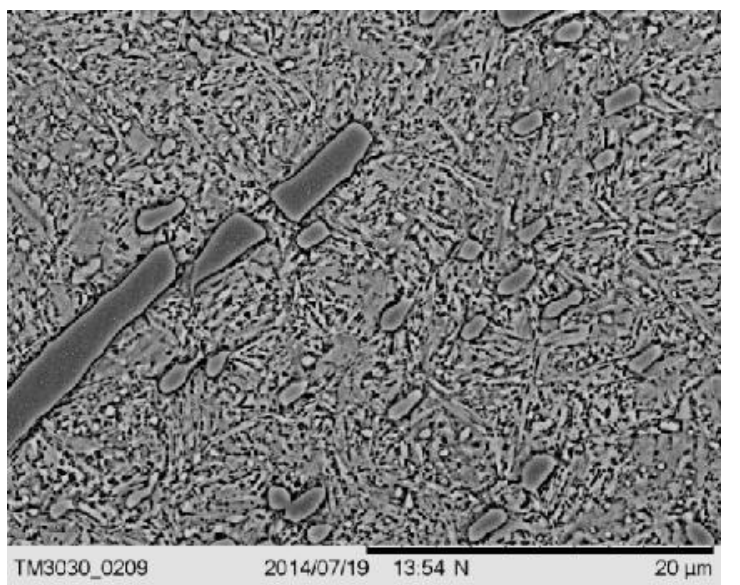

(a)

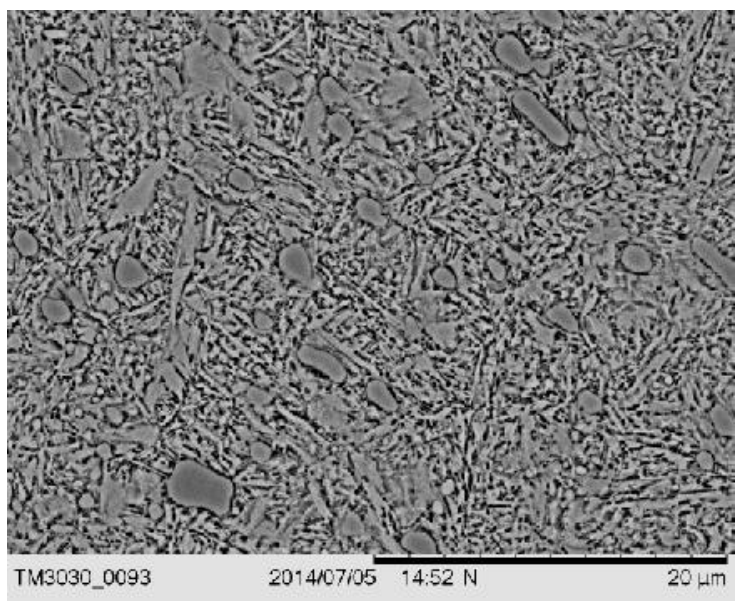

(b)

Fig.3 


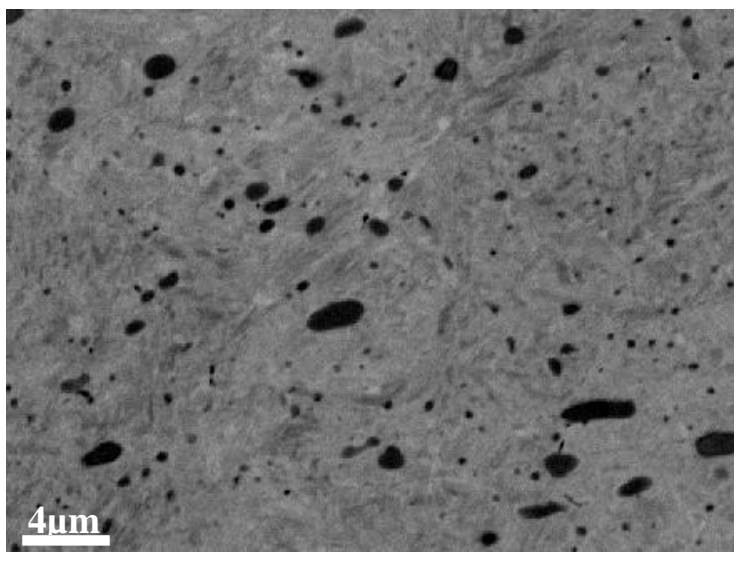

(a)

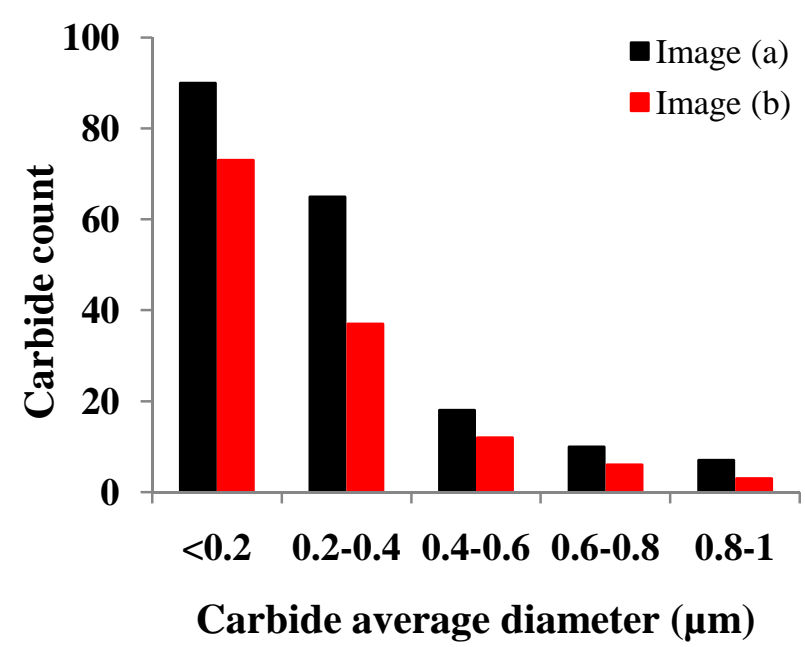

(c)

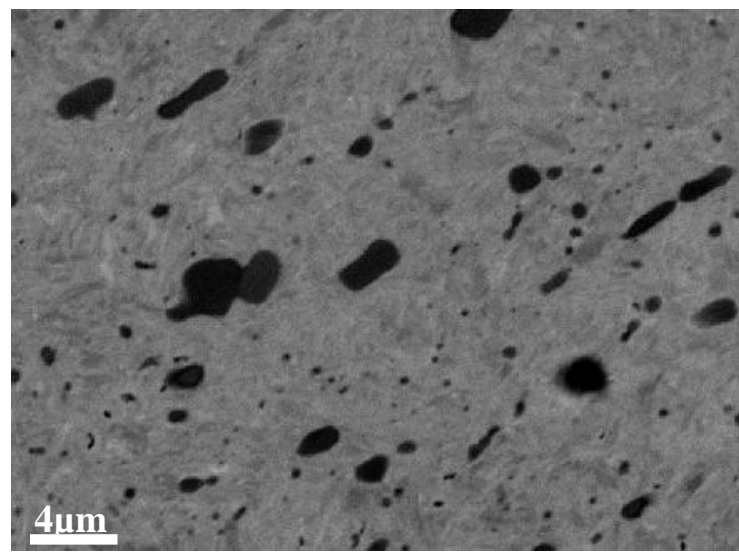

(b)

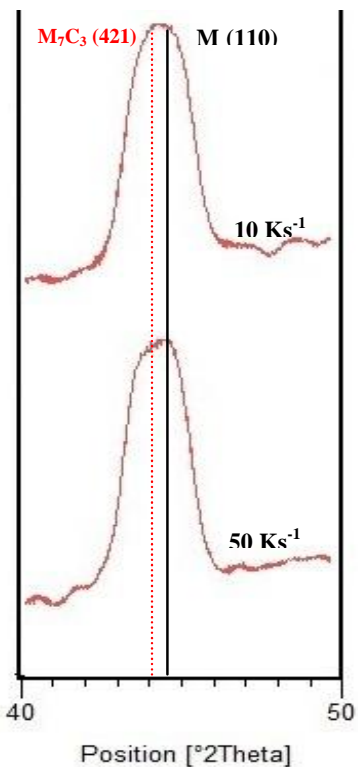

(d)

Fig.4 


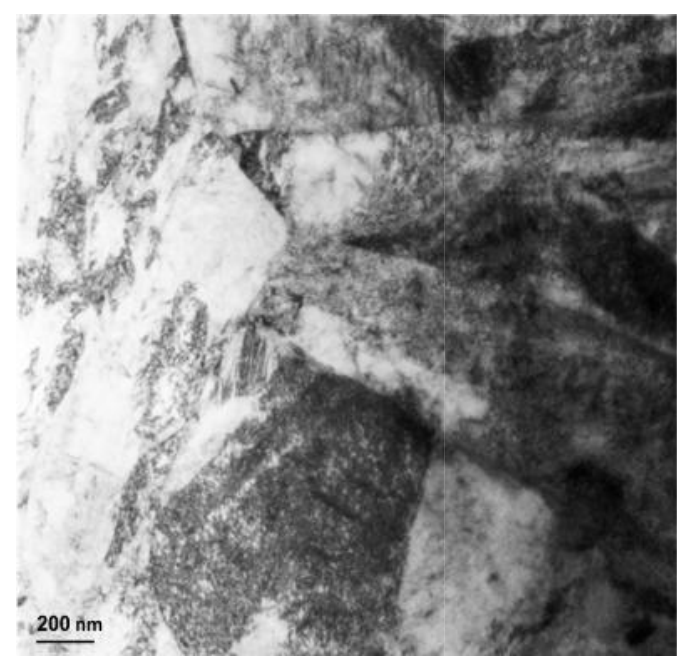

(a)

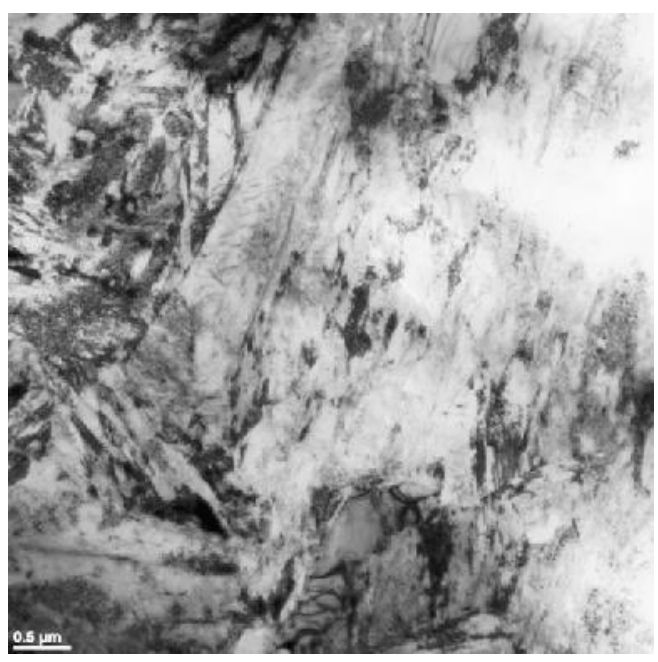

(b)

Fig.5 


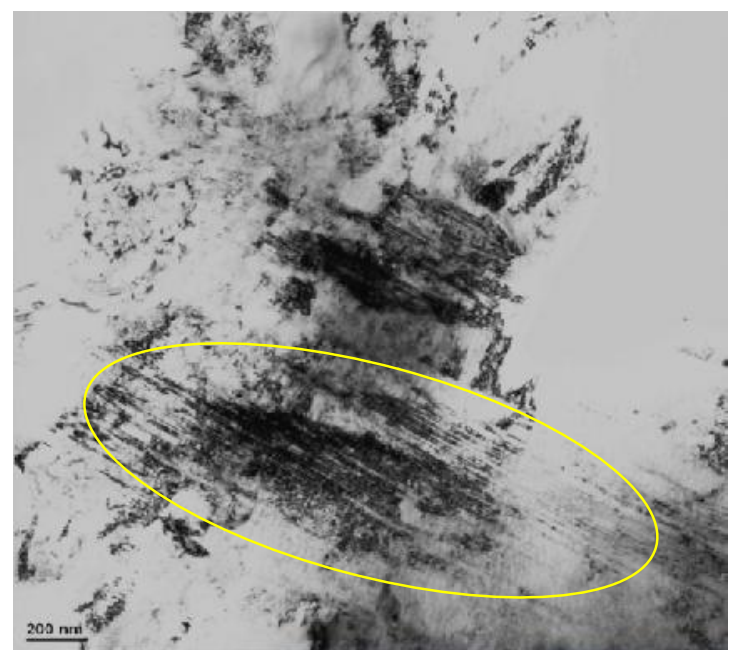

(a)

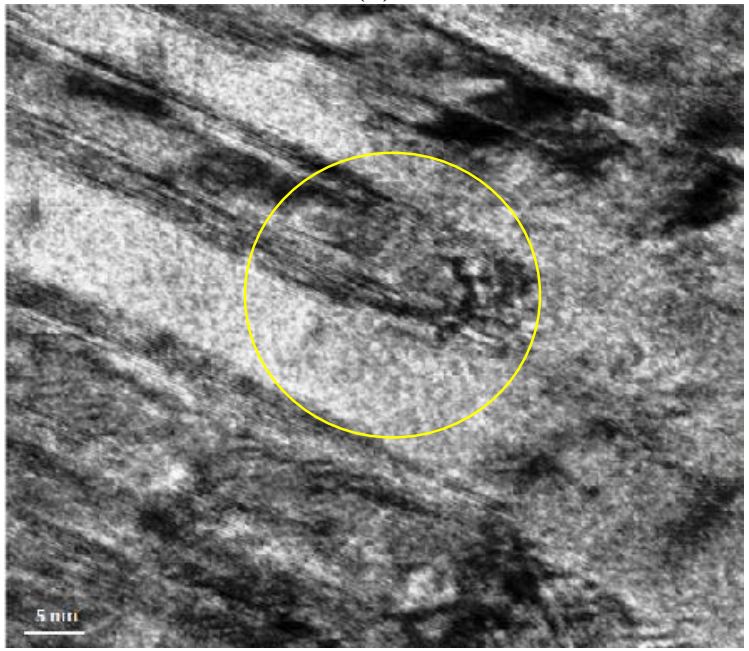

(c)

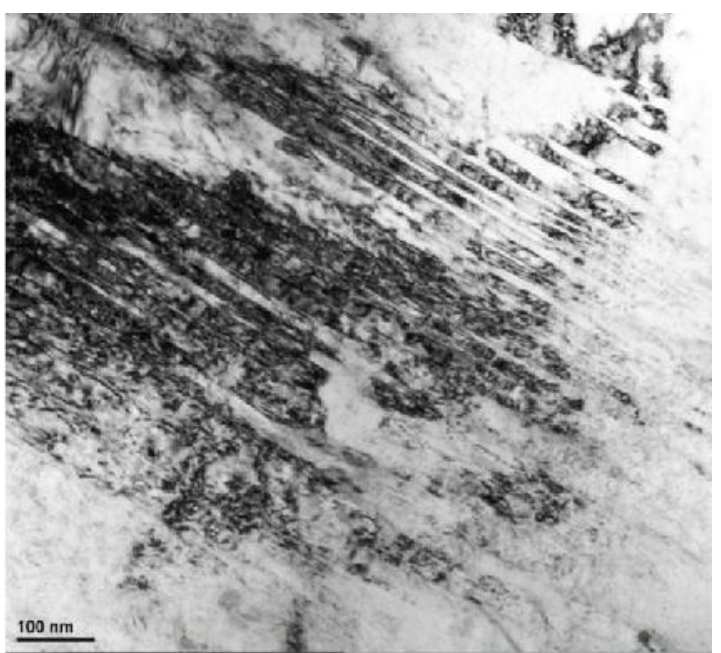

(b)

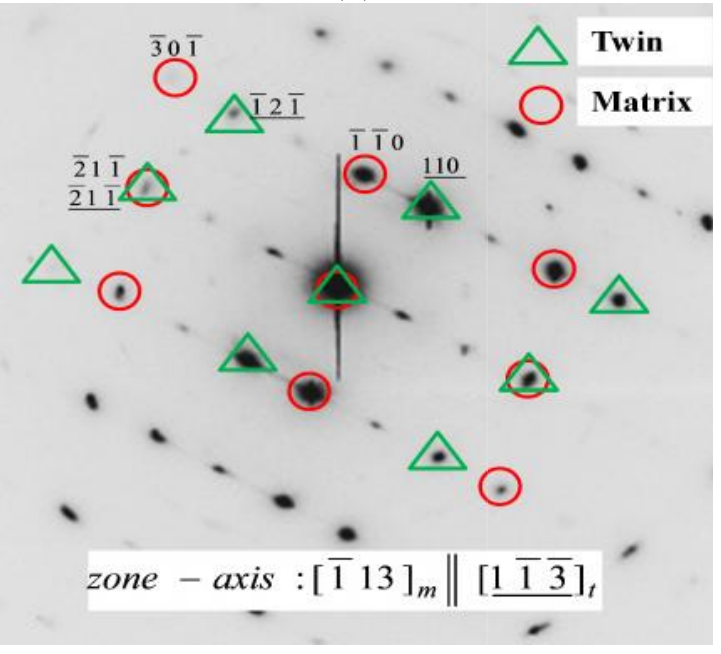

(d)

Fig.6 


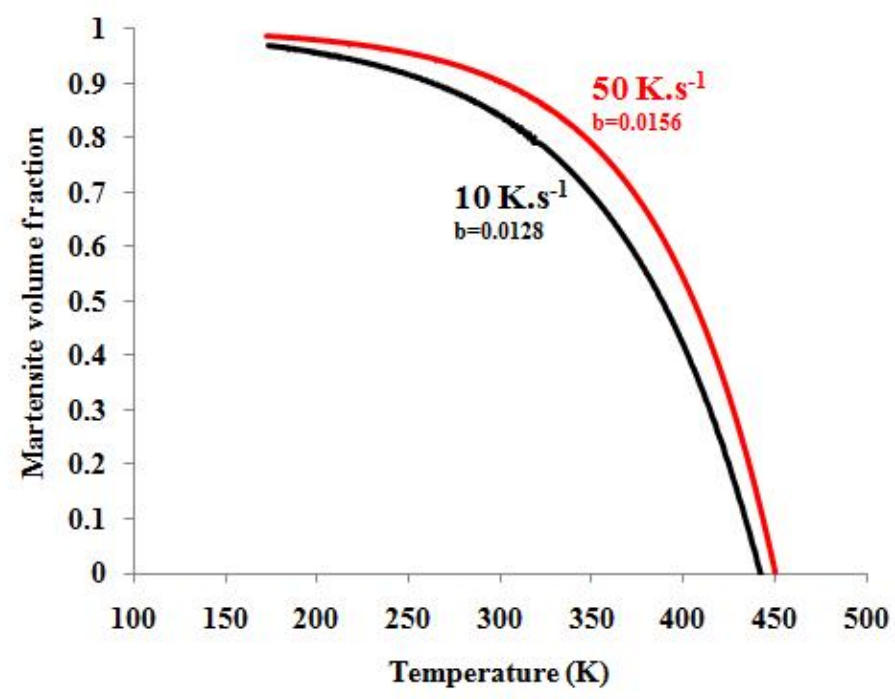

Fig. 7 


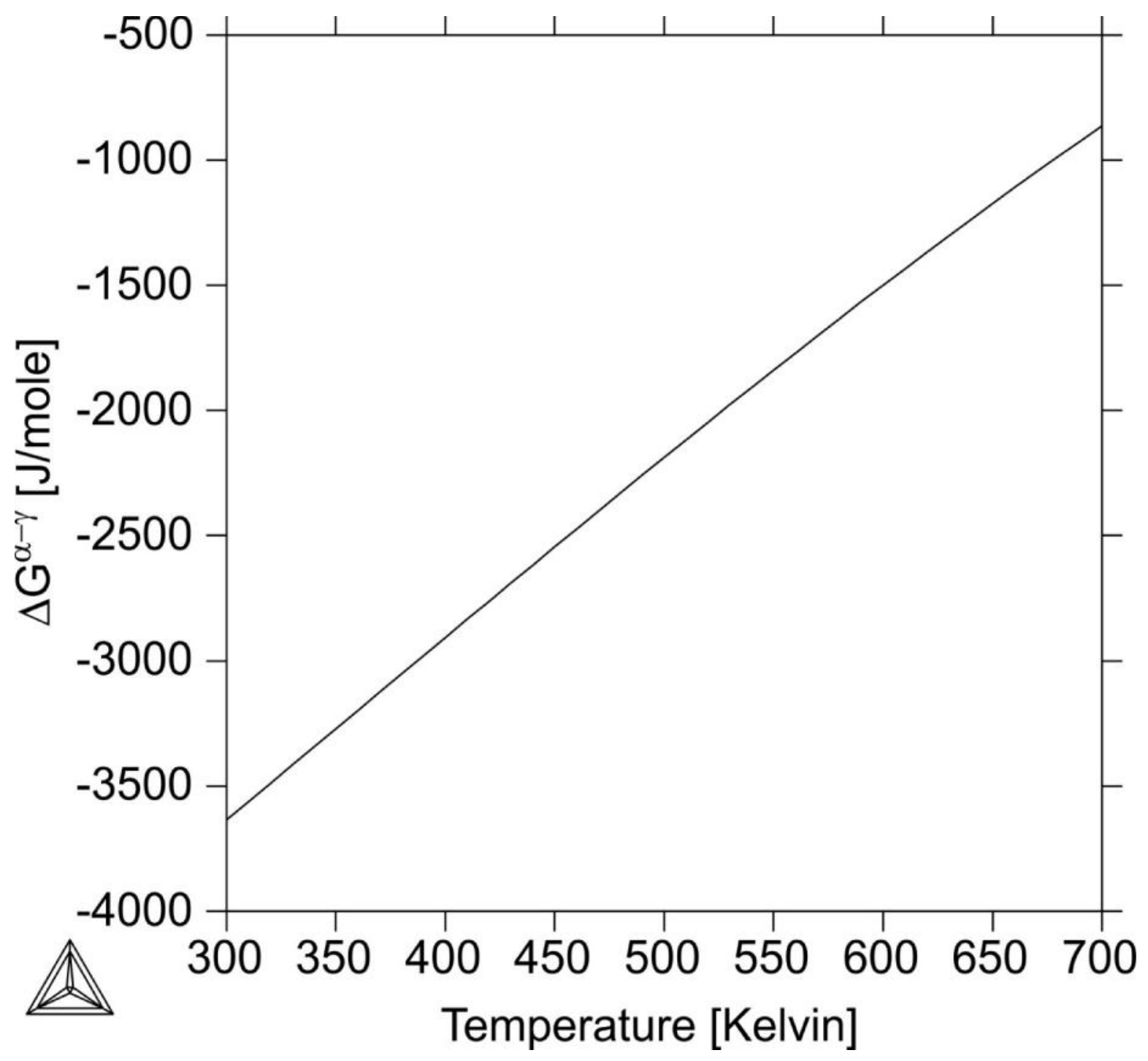

Fig.8 
Table 1 Data used for curve fitting for both $10 \mathrm{~K} \mathrm{~s}^{-1}$ and $50 \mathrm{~K} \mathrm{~s}^{-1}$ cooling rates

\begin{tabular}{|c|c|c|}
\cline { 2 - 3 } \multicolumn{1}{c|}{} & \multicolumn{2}{c|}{ Cooling rate } \\
\hline Variable & $\mathbf{1 0 ~ \mathbf { K ~ s } ^ { - 1 }}$ & $\mathbf{5 0 ~ \mathbf { K ~ s } ^ { - 1 }}$ \\
\hline$E_{0}$ & -0.00326 & -0.00334 \\
\hline$\alpha_{m}\left(\times 10^{-6} / K\right)$ & 9.36 & 8.48 \\
\hline$b$ & 0.0128 & 0.0156 \\
\hline$M_{s}$ First derivative method $(\mathrm{K})$ & 470 & 450 \\
\hline$M_{s}$ Calculated by model $(\mathrm{K})$ & 444 & 450 \\
\hline
\end{tabular}

